\title{
INVERSÃO DE PAPÉIS: JOGOS DE GÊNERO E IMAGINAÇÃO LITERÁRIA EM RACHEL DE QUEIROZ
}

REVERSAL OF ROLES: GENDER GAMES AND LITERARY IMAGINATION IN RACHEL DE QUEIROZ

\author{
Clovis Carvalho Britto * \\ * Universidade de Brasília \\ Brasília, DF - Brasil \\ ORCID 0000-0001-6267-544X \\ Paulo Brito do Prado** \\ ** Universidade Federal Fluminense \\ Niterói, RJ - Brasil \\ ORCID 0000-0003-1932-3902
}

\begin{abstract}
Resumo
Este artigo examina os jogos de gênero e a imaginação literária de Rachel de Queiroz. Utilizando fontes produzidas no começo da carreira da escritora propóe aproximações entre história da vida literária e história das mulheres a partir da análise dos embates no espaço literário brasileiro na primeira metade do século XX. O objetivo é destacar o impacto dos papéis que Rachel de Queiroz desenvolveu enquanto mulher indisciplinada nas confluências entre sua trajetória e a arquitetura de seus projetos literários em espaços marcadamente masculinos. Problematiza as estratégias da escritora ao inverter os papéis destinados às mulheres e reinventar espaços de liberdade no âmbito da profissionalizaçáo e da produçáo de repertórios sobre a diferença entre os sexos.
\end{abstract}

Palavras-chave: Rachel de Queiroz; história das mulheres; gênero; literatura.

\section{Abstract}

This paper examines Rachel de Queiroz's gender games and literary imagination. Using sources produced at the start of the writer's career, this article suggests a parallel between the history of literary life and the history of women drawn from analysing conflicts in the Brazilian literary space in the first half of the twentieth century. The objective is to highlight the impact of

\section{Resumen}

Este artículo examina los juegos de género y la imaginación literaria de Rachel de Queiroz. Utilizando fuentes producidas al comienzo de la carrera de la escritora propone acercamientos entre historia de la vida literaria e historia de las mujeres a partir del análisis de los embates en el espacio literario brasileño en la primera mitad del siglo XX. El objetivo es destacar el impacto de los 
de Queiroz's role as an undisciplined woman in the confluences between her trajectory and the architecture of her literary projects in markedly masculine spaces. We problematize the writer's strategies by reversing roles for women and reinventing free spaces in the area of professionalization and the production of repertoires on the difference between the sexes.

Keywords: Rachel de Queiroz; history of women; gender; literature. papeles que Rachel de Queiroz desarrolló como mujer indisciplinada en las confluencias entre su trayectoria y la arquitectura de sus proyectos literarios en espacios masculinos. Problematizo las estrategias de la escritora al invertir los papeles destinados a las mujeres y reinventar espacios de libertad en el ámbito de la profesionalización y la producción de repertorios sobre la diferencia entre los sexos.

Palabras clave: Rachel de Queiroz; historia de las mujeres; género; literatura.

Há um ditado que diz: 'O papel leva tudo'. O mais certo seria dizer: 'O papel (no caso, o jornal) leva a tudo'. Todo o bem e todo o mal do mundo podem nascer de uma folha de diário. Um telegrama falsificado, uma frase apócrifa, já desencadearam guerras. E continuam desencadeando.

Rachel de Queiroz (2004, p. 244)

$\mathrm{Na}$ epígrafe, extraída da crônica "Uma simples folha de papel”, escrita no Rio de Janeiro em 1990, Rachel de Queiroz (2004) chamou atenção para as potencialidades do papel e de seu manuseio no interior da atividade jornalística e escritural. Na prática, para Rachel, uma folha de papel pode levar a tudo. No caso do jornal, o papel, quando manuseado pela articulista, pode desencadear todo o bem e todo o mal do mundo; pode colocar em xeque a profissão daquele que nele escreve e oportunizar versóes outras de temas naturalizados. Daí ser preciso, nessa trêmula serventia do papel e do jornal, hesitar num fraseado, trocar um verbo mais incisivo por outro mais ameno, polvilhar com sal de malícia qualquer flagrante inocente, descobrir interpretaçóes sutis ou subliminares para o que seria apenas massudo e incolor.

Rachel exercita o que Natália Guerellus (2011) chamou de "conciliaçôes". A escritora, por intermédio de romances, buscou as consonâncias: "Do tradicional ao moderno, sua escrita propóem con- 
ciliação" (p. 14). Deve ser por este canal que Rachel se inseriu na cena pública a partir de suas primeiras publicaçóes em jornais cearenses, entre 1920 e 1930 . Pensando nisto, aventamos ter sido ela aceita entre o grupo de intelectuais daquela região porque sua figuração na cena pública "se justificava em nome de valores mais elevados, do bem da pátria e não implicava uma realização pessoal, embora para ela, sem dúvida, esse era um impulso importante" (TELLES, 2013, p. 151).

Segundo Rachel de Queiroz, é necessário administrar o indisciplinado, mostrar comportamentos pouco convencionais e denunciar situaçóes marcadas pela violência, todavia isto precisa ser feito de forma estratégica (CERTEAU, 2009). É claro que em suas imagens as mulheres, suas diferenças e suas identidades geraram alguma "desunião e representaram um desafio à coerência" (SCOTT, 2008, p. 99). Apesar disso, Rachel demonstrou certa engenhosidade em administrar as políticas da história e do cotidiano no qual se inseria. Utilizou-se de táticas, estratégias e acumulou muitos paradoxos ao longo de sua trajetória.

Ao conceber sua imaginação literária, selecionando intençôes e gestualidades, produzindo matrizes discursivas ou tendências de pensamento (CHAGAS, 2003), a escritora explorou as imagens de "mulheres indisciplinadas". Ela imaginou personagens que amavam, flertavam, fumavam, abandonavam, apanhavam, matavam e morriam. Suas mulheres tinham o cotidiano pressionado por transformaçóes imprevistas, e isso as forçava seguir em frente porque a "[...] vida é uma coisa que tem que passar, uma obrigação de que é preciso dar conta" (QUEIROZ, 2004, p. 117).

Rachel manejou poderes e constituiu seu poder feminino, ainda que não tenha se solidarizado com os feminismos. É fulcral ver suas estratégias e suas personagens como reapropriaçóes e desvios "dos instrumentos simbólicos que instituem a dominação masculina, contra o seu próprio dominador” (QUEIROZ, 2004, p. 24). Um exemplo disso é a metáfora da folha de papel. O papel nas mãos da escritora tem o poder de determinar a ordem das coisas no mundo. Tem o poder de deixar falar personagens convencionalmente tomadas como mudas ou incapazes de se pronunciar por si próprias. Nessas reflexôes, Rachel de Queiroz nos faz aludir ao seu trabalho de eleição das mulheres e de suas diferenças. Suas personagens e o seu trabalho 
escritural deixam ver um temário de táticas e estratégias a fim de ocupar os vazios da história, forçar passagem, exercer algum poder ou se converter em vítima desse poder (PERROT, 2005; CERTEAU, 2009).

Rachel de Queiroz sabia o tamanho de sua responsabilidade, tanto que manejou o poder de que dispunha, fazendo-o exteriorizar-se pelo canal da caneta ou da tinta de sua máquina de escrever. Por meio de concessóes, fosse dos pais ou de diferentes proprietários de jornais, ela produziu "mulheres de papel” (LACERDA, 2003). Rachel fabricou indícios que falavam das mulheres e que não eram aquelas representaçóes estereotipadas insistentemente enfatizadas pelos homens de letras. Ao escrever literatura sobre mulheres, Rachel demonstrou outras formas de ser mulher que não se limitavam aos modelos de feminilidade ditados por uma moral burguesa que imaginava a mulher submissa ao homem e aprisionada aos afazeres domésticos (TELLES, 2012).

Sua atividade escritural, suas açóes, suas personagens, seus paradoxos e a reverberaçáo de sua obra nos ajudam a "[...] compreender de forma mais radical, o papel da história escrita na criação das identidades individuais e coletivas, de gênero e classe" (SCOTT, 2008, p. 113). O simples fato de escrever a inscreve na história. E se inscrevendo na história ela altera sua política, exige passagem por espaços onde antes náo tinha sua agência reconhecida. Seu destemor e desembaraço literário permitem-lhe a construção de uma "tradição literária das mulheres" (DUARTE, 1998, p. 128).

Num contexto em que se convencionou esconder a palavra de mulheres atrás de pseudônimos masculinos, vez que não lhes era permitido "[...] a incursão pelas letras, um espaço que se pretendia de domínio exclusivo dos varóes" (DUARTE, 1998, p. 128), faz-se necessário entender a posição de destaque ocupada por Rachel de Queiroz. Além de ousar escrever e publicar, seu ponto de vista "[...] imprime aos textos a marca de um duplo desrecalque, pois neles falam tanto a classe, quanto o gênero oprimido" (ASSIS DUARTE, 2005, p. 108).

$\mathrm{Na}$ literatura de Rachel, falam também as diferenças nas mulheres, tema difícil de abordar, pois se a diferença das mulheres já gerava desunião, a diferença entre elas era questão difícil de compreen- 
der, quiçá de representar (SCOTT, 2008). A escrita de Rachel e sua imaginação literária são de certa forma "uma provocação aos padrôes estabelecidos" (TELLES, 2012, p. 57). Por mais que a escritora tenha reproduzido em sua literatura diferentes aspectos conservadores, não é possível exigir dela uma consciência táo refinada das questóes de gênero já em 1930.

É preciso entender que "[...] certos limites se deslocam mais do que outros, certas zonas resistem mais do que outras". Deste modo, as movimentaçôes de Rachel pelas fronteiras do gênero apresentam-se "como as figuras de um interminável balé" (PERROT, 1998, p. 11). O fato de ousar escrever e eleger as mulheres como personagens constitutivas de sua imaginaçáo literária é elemento suficiente para compreendê-la como alguém que rompeu com certas injunçôes do gênero. Sua escrita é uma recusa às clivagens de gênero em circulaçấo pelo Brasil na década de 1930.

Rachel desde muito jovem escreveu e publicou poemas e crônicas. Com apenas 18 anos, Rachel criara diferentes pseudônimos: Rita de Queluz, Maria Rosalinda, Inocência, Ignez e Zé de Guignol. Esses "escritores fictícios" a permitiam publicar poesias, crônicas e opinióes em jornais do Ceará, sem que fosse facilmente identificada.

Em 18 de março de 1928, O Ceará trouxe nota indicando ser Rita de Queluz quem dirigiria e coordenaria a sessão "Jazz Band" do impresso. Esta era uma sessão literária que, durante longo tempo, o jornal mantivera em suas páginas "[...] abrilhantada pela colaboraçâo das mais encantadoras e admiradas penas do nosso meio beletrista [...]. A sua orientaçáo esta a cargo da inteligente e scintillante [sic] Rachel de Queiroz (Rita de Queluz), um dos mais promissores talentos femininos da geração nova" (SOB A DIRECÇẪO..., 1928, p. 7).

Em 1928, a sessão "Jazz Band" trazia o comentário de Rachel/Rita a respeito do uso de pseudônimos pelas mulheres escritoras, do exercício literário e da ousadia da escrita de autoria feminina:

Li, já faz algum tempo, um escripto [sic] de uma moçoila que não teria talvez dezessete annos [sic]. Fala-nos de seu passado e faz desfilar ante os olhos pasmos de quem a lê o seu primeiro amor, o segundo, o terceiro, o quarto, que é seguido por um etc. abrangedor e significativo... 
Imagine-se o que não contará essa moça quando tiver para campo de reminiscências amorosas um longo passado de trinta annos! [sic] Talvez leve vantagem às divorciadas com que Roma escandalizou o mundo...

Felizmente, creio que o número de amores, já tão crescido para idade tão pouca, não passa de ficção literária, um mero true para obter effeito... [sic]

A's vezes, vê-se na rua uma mocinha seria, vestida de branco, ar ingênuo de "Filha de Maria". Pergunta-se a alguém quem é.

"É" fulana, uma menina muito inteligente, etc. etc. Collabora [sic] em "Verdes Mares".

A gente se interessa.

Folheia a revista indicada a cata do pseudonymo[sic] que nos foi complacentemente ensinado, Prompto [sic]. [...].

Querem escrever?

Porque não compreendiam receitas de doces,

Ou não fazem a tradução das legendas de "La Conquete" ou de "Ouvrages des dames o desespero das pobres costureiras que não tiveram a ensinal-as [sic] a língua gaulesa de uma freira de Sion?...

Os maridos affluirão [sic] aos cardumes, confiantes, encantados, máos estendidas para as algemas da pretoria...

Vistes bem que não é de vós que fallo [sic], ó mulheres de talento da minha terra?

Procuro desimpedir-vos o caminho da multidão de medíocres que o congestiona, e da qual eu me sinto parte... [...].

(SOB A DIRECÇÃO..., 1928, p. 4)

O papel que a leva a tudo encaminhou Rachel para fora da esfera privada. A princípio, sob o véu dos pseudônimos, ela conseguiu ainda muito jovem fazer com que suas opiniōes e convicçóes escapassem para fora da folha em branco, tomando lugar na esfera pública. Sua escrita produziu a ponte entre as esferas, e tornou possível seu trânsito por temas característicos do contexto político, social e econômico em que se inseria. Evidencia os gigantescos investimentos promovidos por Rachel e outras autoras no intuito de obter uma chance literária e para se tornarem protagonistas da cena intelectual, 
construindo nesses moldes uma vida de artista na contramão - à margem das posiçóes ao alcance dos homens - e problematizando a "amadora condição feminina" ou o script a elas pré-determinado (MICELI, 2005).

\section{Papéis de mulheres: literatura como resistência}

Rachel de Queiroz nasceu em Fortaleza, Ceará, em 17 de novembro de 1910. Filha de Clotilde Franklin de Queiroz e Daniel de Queiroz, Rachel teve, conforme apontou Heloisa Buarque de Hollanda, uma "vida itinerante". (QUEIROZ, 1967, 2004; HOLLANDA, 2004). Durante a infância, "[...] dividiu-se num ir e vir entre a cidade e o campo, entre Quixadá e a Fazenda do Junco" (HOLLANDA, 2004, p. 287) e, após o casamento, acompanhou o marido em suas muitas transferências.

Em reportagem publicada no dia 31 de julho de 1941, o jornal Diretrizes afirmou que, após seu casamento com o intelectual e funcionário do Banco do Brasil José Auto, Rachel deu início a uma "[...] vida nômade, pois tendo de acompanhar o marido nas suas diversas transferências, andou de cima para baixo" (DIRETRIZES, 1941). Contudo, é preciso considerar que esses deslocamentos não anularam a trajetória literária, plasmada no trânsito entre os mais variados lugares e regióes do Brasil.

Em sua infância e adolescência, Rachel viveu no Ceará, no Rio de Janeiro e em Belém do Pará. Embora todo esse trânsito tenha se tornado parte constitutiva de sua trajetória, é a fuga da Fazenda do Junco, em 1915, que influenciou sua obra literária. Foram das memórias dos retirantes e fugitivos da grande seca deste ano que a "[...] menina adolescente, [portadora] de uma imaginaçáo larga, um poder de síntese admirável, um estilo forte e experimentado" (HOLLANDA, 2004), teceu $O$ Quinze, obra muito festejada e bastante polêmica por ser fruto da "imaginação literária" de uma mulher. (TELLES, 2012) Com a publicação do romance, seguido do prêmio Graça Aranha em 1931, Rachel de Queiroz viu seu nome ser projetado e "espalhado por todo o Brasil, analisado e aceito pela crítica mais exigente" (HOLLANDA, 2004). 
Apontamos a necessidade de observar essa "aceitação" com certo cuidado. Embora $O$ Quinze tenha sido muito bem recebido pela crítica, sua "aceitaçáo" não blindou a autora dos efeitos da dominação masculina: subalternização, desprezo e misoginia. Como o espaço literário e intelectual era/é caracterizado pelo sexo masculino, que se responsabiliza "pela formação de cânones literários [costumeiramente excludentes da] mulher como produtora de cultura" (DUARTE, 1998, p. 128), Rachel precisou elaborar estratégias para contornar a misoginia e a violência simbólica que pairava sobre o ambiente intelectual brasileiro de fins da República Velha (SOIHET, 1989).

A violência simbólica foi elemento constitutivo de sua trajetória intelectual e profissional. Em diferentes momentos, Rachel utilizou sua escrita, muito caracterizada por personagens do sexo feminino, fortes, duras e ríspidas, como um mecanismo de resistência aos conflitos de gênero, resultantes de sua entrada em um espaço convencionalmente representado pelo protagonismo masculino (DUARTE, 1998). Sua imaginação literária e seus personagens "convivem com o empenho em abalar a ordem falocêntrica, agravada entre nós pelos ecos ideológicos oriundos da casa grande e das muitas senzalas" (ASSIS DUARTE, 2005, p. 110).

Rachel de Queiroz foi vítima da crítica literária masculina inúmeras vezes. E esta crítica em grande parte utilizou, como mecanismo de invalidação de sua literatura, a dúvida e a crença de que as mulheres não eram capazes de abstrair sua intelectualidade. Nesse aspecto, a conquista de Rachel significou uma exceção, pois ler, escrever e pensar não era encarado como uma atividade feminina. Quando as mulheres tentavam exercitar a escrita, se chocavam com diferentes obstáculos, uma vez que ao "[...] se contemplarem no espelho, o que viam eram imagens-máscaras que os textos de homens desenharam para elas" (TELLES, 2012, p. 62).

Para muitos, $O$ Quinze tratava-se de livro produzido por homem. Um dos exemplos mais clássicos da desconfiança masculina é a dúvida levantada por Graciliano Ramos, que mesmo diante da fotografia de Rachel insistiu em atribuir o romance ao "sexo barbado". (HOLLANDA, 2004; GUERELLUS, 2011). Porém, é possível observar essas desconfianças em outras publicaçôes. Em 2 de agosto de 1930, na sessão "Balcão Florido", a revista Fon-Fon publicou o 
texto "Letras femininas". Nessa matéria foi exibida a fotografia de Rachel de Queiroz e um texto comentando a obra, combinando-a a alguns elementos constitutivos de sua trajetória. O documento deixou evidente o alarde e a surpresa que causou Rachel de Queiroz, "aos dezenove annos, $[s i c]$ idade em que a mulher, geralmente não gosta de pensar" ter escrito e publicado $O$ Quinze, “[...] um livro de sensibilidade e observaçáo, profundo e forte, singelo e amargo como todos os dramas angustiantes da vida" (LETRAS FEMININAS, 1930).

Segundo a revista, tal fato fora encarado com certo exotismo e excentricidade, pois náo eram comuns mulheres jovens se preocuparem com a reflexáo e a intelectualidade. Era preciso considerar que "escrever um bom romance é ainda mais difficil [sic]". A matéria concluiu que ninguém seria "[...] capaz de acreditar que [O Quinze fosse] escripto [sic] por uma jovem que não [contava] ainda vinte anos". Porque se tratava, "[...] com effeito [sic], de uma obra digna do successo [sic] com que, certamente, a consagrará a opiniáo de todo o Brasil que lê e sabe apreciar devidamente os bons livros" (LETRAS FEMININAS, 1930). A imagem de que a "[...] obra digna de successo [sic]" não poderia ter sido escrita por uma mulher remetia à ideia de que às mulheres cabia apenas se enveredar timidamente pelo universo da poesia, por textos romanceados e/ou "aguados".

Rachel, mesmo iluminada pelos holofotes de câmeras e pelo assédio da imprensa, não teve sua produção plenamente considerada. Apesar de festejada entre alguns escritores brasileiros de sua época, havia um comentário ou outro questionando sua capacidade intelectual e até a sua sexualidade.

O fato de ser mulher era razão suficiente para duvidarem de sua capacidade intelectual em imaginar personagens que colocariam em xeque a virilidade masculina. Sobre isso Durval Muniz (2001, p. 97) apontou que o processo de virilização das mulheres foi acompanhado da sensação de "[...] enfraquecimento dos homens, que não foram capazes mais de atualizar os antigos modelos de comportamento masculino, contribuindo para a ruína das famílias e das propriedades". Talvez esteja aí parte do medo que o trabalho intelectual e pensamento político de Rachel provocaram entre muitos homens. 
Utilizando personagens e se comportando de forma pouco convencional ao seu sexo, Rachel demonstrou "[...] como o gênero opera inexoravelmente até no mais abstrato e no menos representativo dos trabalhos e nos padróes aplicados para julgá-los" (SMITH, 2003, p. 19). Em suma: sua imaginaçáo literária legou papéis que noticiam e denunciam os silêncios da história: as mulheres. As "mulheres de papel” tecidas por Rachel contam uma versão que a história e suas políticas pretenderam manter trancadas nos quartos e alcovas. Sem seus registros, essas mulheres continuariam "anarquivadas" (DUARTE, 2007) e dispersas em um universo de memórias inabitadas.

Em suas memórias, colhidas e editadas pela irmã Maria Luiza de Queiroz, Rachel contou como sua formação intelectual havia sido influenciada pela máe e pelo pai. Segundo a escritora, essa influência a havia ajudado a exercer, ainda muito jovem, diferentes papéis: professora, escritora, jornalista, tradutora, intelectual e mulher atuante e influente, pelo menos no Ceará.

A visibilidade que $O$ Quinze recebeu após sua segunda edição e premiação foi crucial em sua trajetória. A recepção favorável do livro converteu-se em uma de suas credenciais mais importantes, responsável, inclusive, por lhe permitir figurar entre grupos literários fortemente caracterizados pelo protagonismo masculino.

Rachel era a única mulher que integrava o denominado "romance de 1930”, composto por José Américo de Almeida, Graciliano Ramos, José Lins do Rego, Érico Veríssimo e Jorge Amado. Temos a impressão de que seu cuidado na composição da trama de $O$ Quinze, somado às mais variadas publicaçóes e a seu comportamento um tanto "diferenciado" para aquilo que se convencionou entender como "conduta feminina" do período, ofereceu-lhe condiçóes para operar, no jogo de gênero, diferentes estratégias e táticas.

Pelo que nos legou, por suas experiências e por sua predisposição em atuar como jornalista profissional, ingressar no mundo da política, militar no Partido Comunista e participar do movimento trotskista (GUERELLUS, 2011), podemos reconhecê-la como uma "exceção", ainda que obedecesse a certas "regras" ditadas por injunçóes de gênero. Regras essas que vão aparecer ao longo de sua trajetória, quando se negou a reconhecer os feminismos ou no momento em que apoiou a ditadura militar em 1964 (GUERELLUS, 2011). 
Embora fosse uma exceção, uma mulher "diferenciada”, Rachel não acreditava no feminismo; muito pelo contrário, afirmava ter "[...] horror das feministas; [pois] só chamavam-na de machista. [Ela achava] o feminismo um movimento mal orientado. Por isso, sempre [tomou] providências para não servir de estandarte para ele" (QUEIROZ, 1997, p. 26). Mesmo assim, sua relação com as sufragistas já vinha sendo especulada como mecanismo para desprestigiá-la desde os anos 1920.

Em matéria de 30 de março de 1928, Rachel foi evocada como "sufragista", de forma que tal atitude representasse desprestígio a "mulher honrada" (SOIHET, 1989). A condução das relaçóes de Rachel ao comunismo e ao sufrágio caminhava de modo que ofendessem a honra sexual das mulheres militantes (SOIHET, 2013). Seu comportamento era danoso para "[...] a autoridade moral da Igreja e do Estado, a inviolabilidade e a reputação pública da família, a autoridade paterna privada, a integridade individual ou o patrimônio familiar" (CAULFIELD, 2000, p. 59). É por essa razão que uma carta contrária às suas publicaçôes no jornal $O$ Ceará fora remetida ao seu pai:

Na secção A's Quintas, do O Nordeste de hontem [sic], um pae [sic] depois de aconselhar sua filha a não ler as revistas cariocas, diz o seguinte:

- Mas papae [sic] acha que uma revista elegante do Rio seja capaz de causar grandes males?

- Grandes e muitos. A má leitura é de uma nocividade fulminante. Muitos jovens que ahi[sic] andam hoje escandalizando o próximo não foram aprender muito longe os seus modos. Quer uma prova? Ahi [sic] está a literata Rita de Queluz. [...]

- Tornou-se, então, bolchevista?

- Ou bolchevista ou sufragista, ou o que seja, o certo é que esta fazendo destempero em literatura, sacrificando a formosura da sua alma, que é a formosura mais linda da mulher. Si assim age com o intuito de se mostrar, maior ainda o desastre. Para a mulher sobressair-se nas lides literarias [sic] o terreno é amplo e ella [sic], si tem talento, se pode jazer notada sem precisar de recorrer aos processos 
repugnantes do atheismo [sic] e do combate às crenças catholicas [sic]. (AS GROSSERIAS ..., 1928b, p. 1).

Tal crítica havia sido produzida pelo jornal católico $O$ Nordeste, cujo fazer jornalístico se opunha ao do jornal $O$ Ceará. Como as lideranças políticas e oligárquicas se opunham ao controle católico sobre a populaçáa, era bastante comum explodirem conflitos do gênero, que tentavam impedir, por exemplo, as mulheres de "sair" para exercer suas influências junto às portas do poder (PERROT, 2005). Em suas memórias, Rachel lembrou como se organizou o conflito, e de que forma seu pai se comportou diante da referida oposiçăo à sua atividade literária.

Enquanto $O$ Nordeste tecia críticas à família que autorizava "uma jovem pura" a escrever para "O Condenado", (como chamavam $O$ Cearâ), seu editor Ibiapina escreveu ao pai de Rachel explicando que, a fim de protegê-la das "maledicências", não publicaria mais nenhum texto assinado pela jovem ou por seus pseudônimos. A reação de Daniel, pai de Rachel, foi rápida. "Do Junco, respondeu que não, estava tudo bem, e se $O$ Nordeste continuasse a falar mal, podia deixar com ele" (QUEIROZ, 2004, p. 31).

Autorizada a escrever, Rachel seguiu publicando seus poemas e suas crônicas, e logo espraiou sua produçáo para outros jornais da regiáo. A persistência em escrever e publicar reforçou ainda mais seu caráter emancipado e liberalizado. Rachel persistiu fortemente atrelada à emancipaçáo, e sua obra continuou inspirando medo, insegurança e irritação nos leitores pouco tolerantes à mulher que lhes afigurava.

Em investigação sobre a obra de Rachel, Osmar Pereira Oliva (2014) apontou uma chave de análise para a atividade intelectual da escritora, para suas personagens e para o silêncio da crítica no que tangencia sua obra. Segundo o estudioso, as personagens de Rachel "[...] rompem com o modelo tradicional e patriarcal de família e escolhem um modo de vida divergente do que é comumente aceito na sociedade brasileira do início do século XX". Porém, toda "[...] liberdade de escolha e poder de decisão não é suficiente para garantir a felicidade para nenhuma delas, o que nos conduz à seguinte reflexáo: de que valem o feminismo e o socialismo se a mulher continua 
infeliz?” (OLIVA, p. 414). De certa forma, Osmar Oliva perseguiu a interpretação de Heloisa Buarque de Hollanda (2002), que destacou ter sido Rachel menosprezada pela crítica por conta do medo que sentiam dela, de seu posicionamento emancipado, de sua imaginação literária e de suas personagens muito contrárias às regras do gênero e da dominação masculina.

Conforme informações encontradas nos jornais $O$ Ceará (1928), A Esquerda (1928), A Razão (1929) e na revista O Cruzeiro (1957), Rachel utilizou por algum tempo uma variedade de pseudônimos. "Rita de Queluz", utilizado para publicar seus primeiros escritos, aguçou nossa atenção, por serem suas iniciais " $R$ " e "Q" quase um anagrama de seu nome. Tal coincidência nos estimulava a perguntar: já teria Rachel consciência de seu talento? Já previra ser adiante uma das escritoras mais celebradas do Brasil, ou tinha dimensão de sua visibilidade in tempore?

\section{Mulheres de papel: a resistência na literatura}

Peregrino talento joven [sic] e culta, Rita de Queluz merece dignamente a admiração de todo o nosso meio. [...] Não estando no tempo inquisitorial, vivemos um regime de liberdade de crenças em que, portanto, o intellectual [sic] pode e deve ter o direito de externar as suas opiniōes. (AS GROSSERIAS..., 1928a)

Com esse pensamento, um grupo de intelectuais cearenses assinou um manifesto em defesa dos posicionamentos de Rachel de Queiroz / Rita de Queluz na imprensa dos anos 1920. Doze homens emprestavam sua assinatura para defender não apenas a liberdade de expressão daquela cujo direito estava sendo ameaçado, mas a liberdade de gênero.

Segundo Michelle Perrot (2005), mulheres muito "ativas" e atuantes assustavam os homens. Sobre isso, a historiadora apontou que o protagonismo feminino, a saída delas para trabalhar, manejar máquinas, desempenhar funçóes naturalizadas como masculinas, colocavam em xeque a "virilidade" masculina. O discurso da "virilidade" era o "discurso sobre a natureza feminina" (PERROT, p. 225). 
Mulheres que contrariavam essa ordem, as naturalizaçóes e injunçóes do sexo, provocavam medo e insegurança e, por esta razão, eram combatidas, apagadas e silenciadas na genealogia dos escritores dignos de crédito. Não por acaso, Rachel de Queiroz reconhecia a literatura como uma atitude de revanche:

'E ignorando a ocasião da estranha empresa pasma da turba feminil'. Santa Rita Durāo: 'Caramuru'. [...]

Vem de longa data - Narcisa Amalia, Francisca Julia, Julia Lopes de Almeida bem o attestam [sic] - o pendor das brasileiras para as bellas [sic] letras. [...]

Dado, pois, o caracter [sic] inteiramente infenso, dos nossos troncos ethnicos[sic] a toda e qualquer relleidade [sic] literária, só se explica a inclinação do brasileiro para os exercícios intelectuais, por um extraordinário fenômeno de revanche.

Temos de exibir literatura com abundancia e qualidade sufficiente [sic] para desmentir a desoldora [sic] fama de escuridáo mental de nossos avós, ou relega-la ao canto escuro onde se somem todas as pequeninas misérias da humanidade... (CHRONICAS..., 1928, p.4).

Nesse aspecto, compreendemos que a trajetória de Rachel, sua profissionalização, suas açóes, suas personagens e o ato bastante subversivo da escrita feminina afrontaram o cenário masculino no qual se inseria. Suas personagens pareciam ser uma representação do que a própria escritora tomara como posicionamento feminino. Não falamos aqui de uma "virilização" ou "masculinização" de suas personagens nem mesmo da escritora. Era uma mulher que tomara para si o desejo de exteriorizar outras experiências, de viver a vida do modo como escolhera, mesmo que isso contrariasse a ordem ditada por um mundo conjugado no masculino.

Conforme sublinhou o jornal A Razão, em 22 de maio de 1929, um grupo de mulheres intelectuais se despontava no Ceará, representado pelas escritoras Adília de Albuquerque Moraes, Suzana de Alencar Guimarães, Adelaide e Judith Amaral, Alba Valdez, Henriqueta Galeno, Elvira Pinho, Maria Cavalcante, Stella Rubens Monte e Rachel de Queiroz (A MENTALIDADE..., 1929). Esse fato atesta 
que Rachel encontrou um cenário mais favorável à expressão literária de autoria feminina e, desde muito jovem, soube mobilizar os trunfos em busca de sua profissionalização, embora ainda enfrentando muitos percalços, segundo relatou a escritora Adília Moraes:

Quando attendendo [sic] á nímia gentileza do illustre [sic] Diretor d'esta folha, assumimos, desde o inicio, a direçáo de sua pagina litteraria [sic], era desejo nosso que fosse ella [sic], em sua mór [sic] parte, colaborada pelo elemento feminil.

Matinas verias, impediram-nos de realizar esta aspiração, logo em começo. - Há grande desanimo entre as intelectuaes [sic] conterrâneas: - a indifferença [sic] d'uns a ironia de outros, o descaso de terceiros, diminuem e represam os surtos de intelligencia [sic], que, bafejados por uma orientação segura, se encaminhariam para nobres e profícuos fins.

Foi procurando despertal-as [sic] do letargo em que entorpecem os brilhos do espirito, que nos propusemos a visital-as [sic], a todas convidando-as a erguerem suas vozes que náo podem calar-se n'uma epocha [sic] em que, de sul a norte do Paiz [sic], nossas irmãs se agremiam para pugnar e vencer.

Após trocarmos idéas [sic] com distinctissimas [sic] patrícias, já obtiveramos [sic] o apoio indispensável d'estes phenomenos [sic] de intelligencia [sic] precoce que são Susana de Alencar e Rachel de Queiroz. (VALORES DESPREZADOS, 1929).

Indisciplinada, Rachel não aceitou se calar, ou mesmo ficar nas sombras da história. Em 1930, no mesmo mês em que publicou O Quinze, tornou-se membro fundadora da Academia de Letras do Ceará, agremiação literária que ostentava cinco mulheres entre seus 40 sócios. (ACADEMIA..., 1930). Todavia, frequentar espaços então interditos às mulheres era motivo para escândalos: "[...] era um dos escândalos que eu causava em Fortaleza, mocinha, frequentando o café dos literatos. [...] Uma moça sozinha num meio quase que só de homens, alguns da minha idade, outros mais velhos". (QUEIROZ, 2004, p. 38) 
Na mesma década, Rachel de Queiroz se mudou para Alagoas, integrando a chamada "Roda de Maceió", composta por intelectuais como Aurélio Buarque de Hollanda, Graciliano Ramos e José Lins do Rego. A independência que foi conquistando ao longo de sua trajetória reverberou em algumas mulheres representadas por sua imaginaçáo literária, marcadas pela explicitação de uma memória no/do feminino e da conquista de uma voz pelas mulheres do sertão.

A partir do exame dos papéis que integram os acervos pessoais da escritora ${ }^{1}$, centramos as análises em sua trajetória, na arquitetura de seus projetos literários e no modo como representou as mulheres sertanejas ao ponto de se tornarem tipos ideais. Dessa forma, visualizamos como a obra de Rachel desconstrói e afirma tensóes tradutoras de configuraçóes hierárquicas de poder a partir dos gestos de lembrança e esquecimento.

Para tanto, nos respaldamos na pista deixada por Heloísa Buarque de Hollanda (2002), quando destacou que as imagens femininas dos romances de Rachel de Queiroz são paradigmas de um Brasil arquetípico e familiar, tornando, de certo modo, uma voz dissonante ao realizar em seus escritos uma profunda identificação do universo feminino com o universo de um poder regional quase histórico.

Ainda sobre o universo feminino de Rachel, Lígia Chiappini (2002) apontou que seus livros tratam de mulheres, mesmo quando os protagonistas são homens. Nesse aspecto, demonstra como sua fortuna crítica tem destacado uma dupla particularidade em suas narrativas, da mulher associada à região e, por sua vez, à nação (ALBUQUERQUE JUNIOR, 2001; 2011). Aponta, assim, interessantes indagaçôes em torno dos limites e possibilidades representadas pelas mulheres de Rachel e o modo como as construçôes de gênero se relacionam com a construção da região, que o Brasil se cobre e descobre a partir do sertão e de que forma suas personagens perpassam outras vozes, presenças, quereres e poderes.

Nesses termos, as protagonistas de Rachel de Queiroz revelam, no dizer de Maria de Lourdes Barbosa (1999, p. 103), papéis, formas de ação, práticas de resistência, recusa, transgressão e sujeição,

1 O acervo pessoal de Rachel de Queiroz está acomodado no Memorial Rachel de Queiroz, em Quixadá-CE, e no Instituto Moreira Salles, no Rio de Janeiro-RJ. 
oferecendo um painel valioso do lugar do feminino em busca da sua realização pessoal. Analisando o perfil das personagens Conceição, Noemi, Guta, Dôra e Maria Moura, conclui que "[...] as protagonistas avançam tentando encontrar explicaçóes que deem sentido a esse caminhar e, assim, vão repassando sua experiência às suas sucessoras".

Pensamos que, ao eleger mulheres de forte personalidade e ao agir de forma bastante liberal, Rachel colocou o dedo na ferida mais profunda da dominação masculina. Ela apontou o "calcanhar de Aquiles" dos homens. Temendo a perda da virilidade e insatisfeitos com a possibilidade de atomizaçáo da identidade masculina em inumeráveis tipos de masculinidades, os homens reagiram contra diferentes manifestaçôes femininas que tentavam questionar as políticas do gênero.

O protagonismo das mulheres incomodava e gerava diferentes problemas, pois "[...] ainda que o 'homem' pudesse se passar por um sujeito humano neutro ou universal, o caso da 'mulher' é difícil de articular ou representar, porque sua diferença gera desuniáo e representa um desafio à coerência" (SCOTT, 2008, p. 99). Isso evidencia um sistema de dominação pautado em uma "norma masculina e universal" que ignora as demandas das mulheres e a própria capacidade de terem reconhecida sua individualidade. Nesse sentido, "as mulheres são o sexo que não é 'uno', mas múltiplo" (BUTLER, 2015, p. 31).

Esta multiplicidade de identidades foi apropriada por intelectuais e homens muito interessados em apagar as demandas das mulheres, ignorar suas agências, individualismos, identidades, para torná-las impossíveis de serem representadas ou definidas enquanto sujeitos sociais, enquanto indivíduos pensantes. É pensando nisso que entendemos ter sido bastante assustador aos homens do círculo intelectual de Rachel observar seus diferentes papéis na esfera pública e a diversidade dos papéis de mulheres representados por suas personagens.

Nesse aspecto, além de ser uma mulher que em suas memórias reescreve os fatos sob a ótica do feminino, sua literatura também privilegia a vida de outras mulheres. Em outras palavras, seria uma escrita comprometida com os "silêncios" da história. (PERROT, 2005) Desse modo, compete aproximarmos das liçôes de Ligia Chiappini 
(2002, p. 175), quando concluiu que seria interessante problematizar os limites e as possibilidades apresentadas pelas mulheres de Rachel a partir do exame das intersecçóes entre o constructo histórico-social de gênero e o constructo da regiáo e da nação. Nesse sentido, sublinha o que denota uma leitura singular na medida em que "[...] suas heroínas saem do útero, da regiáo e da casa grande para ganhar a rua, e mais que a rua, a estrada, chegando às pensóes das cidades, às suas escolas, lendo, estudando e escolhendo livremente parceiros e profissóes."

A vida e obra de Rachel de Queiroz se mesclam, deslocando os diferentes papéis de mulheres no Brasil do início do século XX. As confidências depositadas nas folhas em branco contribuíram para a reinvenção de espaços de liberdade, dinamitando os diques de chances restritas da mulher no âmbito da criação literária e ampliando os repertórios sobre a diferença entre os sexos e entre o mesmo sexo. Talvez, por isso, ao rememorar os embates iniciais enfrentados em função de suas "mulheres de papel", a escritora tenha confidenciado: "Moça não podia ler cena de sexo. Não se usava, era um escândalo dos diabos. [...] Quando eu escrevi João Miguel foi uma mulher lá em casa dizer a mamãe: 'Clotilde, você não acha que João Miguel tem cenas muito cruas para Rachelzinha ter escrito?”. Rachel de Queiroz concluiu suas memórias sublinhando a resposta de sua mãe: "Pois é, se não fosse ela que tivesse escrito essas cenas eu não deixava que ela lesse...' Mamãe falou de gozação, mas a mulher saiu muito consolada”. (QUEIROZ, 2004, p. 35)

\section{Referências bibliográficas}

A MENTALIDADE FEMININA CEARENSE. A Razão, Fortaleza, ano I, n. ${ }^{\circ}$ 61, 22 maio 1929, p. 2.

ACADEMIA DE LETRAS DO CEARÁ. A Razão, Fortaleza, 11 jun. 1930, p. 7.

ALBUQUERQUE JUNIOR, Durval Muniz de. A invenção do Nordeste e outras artes. São Paulo: Cortez, 2011.

. Limites do mando, limites do mundo: a relação entre identidades de gênero e identidades espaciais no nordeste do começo do século. História: questóes e debates, Universidade Federal do Paraná, n. 34, 2001. 
AS GROSSERIAS inéditas na imprensa cearense. O Ceará, Fortaleza, ano III, n. ${ }^{\circ} 841,30$ mar. 1928a, p. 1.

AS GROSSERIAS do órgão catholico provocam protesto. $O$ Ceará, Fortaleza, ano III, n. ${ }^{\circ} 843,1$ abr. 1928b, p. 10.

ASSIS DUARTE, Eduardo. Classe e gênero no romance de Rachel de Queiroz. In: DUARTE, Eduardo Assis. Literatura, politica, identidades: ensaios. Belo Horizonte: Fale/UFMG, 2005.

BARBOSA, Maria de Lourdes Leite. Protagonistas de Rachel de Queiroz: caminhos e descaminhos. Campinas: Pontes, 1999.

BUTLER, Judith P. Problemas de gênero: feminismo e subversão da identidade. Rio de Janeiro: Civilização Brasileira, 2015

CAULFIELD, Sueann. Em defesa da honra: moralidade e nação no Rio de Janeiro (1918-1940). Campinas: Editora da Unicamp, Centro de Pesquisa em História Social da Cultura, 2000.

CHAGAS, Mario de Souza. Imaginação museal: museu, memória e poder em Gustavo Barroso, Gilberto Freyre e Darcy Ribeiro. 2003. Tese (Doutorado em Ciências Sociais), Universidade do Estado do Rio de Janeiro, 2003.

CHIAPPINI, Lígia. Rachel de Queiroz: invenção do Nordeste e muito mais. In: CHIAPPINI, Lígia; BRESCIANI, Maria Stella (orgs.). Literatura e cultura no Brasil: identidades e fronteiras. São Paulo: Cortez, 2002.

CHRONICAS... O Ceará, Fortaleza, 1 abr. 1928, p. 4.

DIRETRIZES. Revista Semanal, Rio de Janeiro, ano IV, n. 58, 31 jul. 1941, p. 5.

DUARTE, Constância Lima. A história literária das mulheres, um caso a pensar. Revista Miscelânea, Universidade Estadual Paulista "Júlio de Mesquita Filho", v. 3, 1998.

- Arquivo de mulheres e mulheres anarquivadas: histórias de uma história mal contada. Revista Estudos de Literatura Brasileira Contemporânea, Universidade de Brasília, n. 30, 2007.

GUERELLUS, Natália de Santanna. Rachel de Queiroz: regra e exceção. 2011. Dissertação (Mestrado em História), Universidade Federal Fluminense, Niterói, 2011.

HOLLANDA, Heloísa Buarque de. As crônicas de Rachel de Queiroz. In: COUTINHO, Fernanda (Org.). Rachel de Queiroz: uma escrita no tempo. Fortaleza: Edições Demócrito Rocha, 2010. 
HOLLANDA, Heloisa Buarque de. Biografia. In: QUEIROZ, Rachel de. Melhores crônicas de Rachel de Queiroz. São Paulo: Global, 2004.

. O éthos Rachel. Cadernos de Literatura Brasileira. São Paulo: Instituto Moreira Salles, n. 4, 2002.

LACERDA, Lilian de. Álbum de leitura: memória de vida, histórias de leitores. São Paulo: Editora Unesp, 2003.

LETRAS FEMININAS. Revista Fon-fon. Rio de Janeiro, ano XXIV, n. 31, 2 ago. 1930, p. 38.

MICELI, Sérgio. Relegação social e chance literária. In: ELEOTÉRIO, Maria de Lourdes. Vidas de romance: as mulheres e o exercício de ler e escrever no entresséculos - 1890-1930. Rio de Janeiro: Topbooks, 2005.

OLIVA, Osmar Pereira. Rachel de Queiroz e o romance de 30: ressonâncias do socialismo e do feminismo. Cadernos Pagu, Universidade Estadual de Campinas, n. 43, 2014.

PERROT, Michelle. Mulheres públicas. São Paulo: Fundação Editora da Unesp, 1998.

. As mulheres ou os silêncios da história. Bauru, SP: Edusc, 2005.

QUEIROZ, Rachel de. A mulher de Lampião. In: FERREIRA, Vera; ARAUJO, Germana Gonçalves de (Org.). Bonita Maria do Capitão: centenário de Maria Bonita 1911-2011. Salvador: Eduneb, 2011. . Melhores crônicas de Rachel de Queiroz. São Paulo: Global, 2004.

- Cadernos de Literatura Brasileira, n 4. São Paulo: Instituto Moreira Salles, 1997.

. O quinze. Rio de Janeiro: Livraria José Olympio Editora, 1967.

QUEIROZ, Rachel de; QUEIROZ, Maria Luíza de. Tantos anos. São Paulo: Arx, 2004.

SCOTT, Joan Wallach. Género e historia. México: FCE, Universidad Autónoma de la Ciudad de México, 2008.

SMITH, Bonnie G. Gênero e História: homens, mulheres e a prática histórica. Bauru, SP: Edusc, 2003.

SOB A DIRECÇÃO [sic] do talento primoroso de Rita de Queluz vae [sic] ser restaurado o "Jazz Band" do "O Ceará". O Ceará. Fortaleza, ano III, n. 331, 18 mar. 1928, p. 7. 
SOIHET, Rachel. Condição feminina e formas de violência: mulheres pobres e ordem urbana, 1890-1920. Rio de Janeiro: Forense Universitária, 1989.

. Feminismos e antifeminismos: mulheres e suas lutas pela conquista da cidadã plena. Rio de Janeiro: 7Letras, 2013.

TELLES, Norma. Encantaçôes: escritoras e imaginação literária no Brasil, século XIX. São Paulo: Intermeios, 2012.

VALORES DESPREZADOS. A Razão, Fortaleza, ano I, n. ${ }^{\circ}$ 59, 19 maio 1929 , p. 3.

Clovis Carvalho Britto é Doutor em Sociologia pela Universidade de Brasília (UnB), Linha de Pesquisa Arte, Cultura e Patrimônio e Pós-Doutor em Estudos Culturais no Programa Avançado de Cultura Contemporânea da Universidade Federal do Rio de Janeiro (UFRJ). Atualmente é Doutorando em Museologia pela Universidade Lusófona de Humanidades e Tecnologias (ULHT - Portugal), e professor nos Programas de Pós-Graduação em Culturas Populares da Universidade Federal de Sergipe e em Museologia da Universidade Federal da Bahia (UFBA). Integra os Grupos de Pesquisa Cultura, Memória e Desenvolvimento (UnB), Museologia, Patrimônio e Memória (UnB), História Regional: Manifestaçóes Artísticas e Patrimônios Culturais (UEM) e Observatório da Museologia na Bahia da Universidade Federal da Bahia (UFBA). E-mail: clovisbritto@unb.br

Paulo Brito do Prado é Mestre em História pela Universidade Federal de Goiás (UFG) e Especialista em Educaçáo para a Diversidade e Cidadania pela Universidade Federal de Goiás/Centro Integrado de Aprendizagem em Rede (UFG/CIAR-GO). Atualmente é Doutorando em História pela Universidade Federal Fluminense (UFF) e professor efetivo na Secretaria de Educação do Estado de Goiás. Áreas de interesse: História das mulheres, Gênero, Sexualidades, Feminismos, Relaçôes Étnico-raciais, Memória, Patrimônio, História Regional, Contemporânea e do Brasil. E-mail: paulobritogo@yahoo.com.br

Recebido em: 16/01/2018

Aceito em: 15/07/2018 